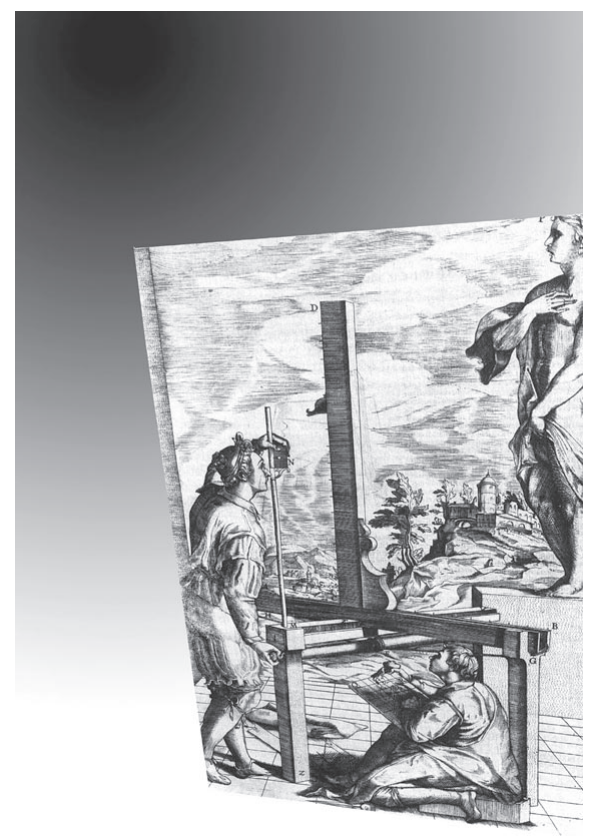




\title{
O GOVERNO LULA E A EDUCAÇÃO: A DESERÇÃO DO ESTADO CONTINUA?
}

\author{
Nicholas DaVies*
}

RESUMO: O artigo faz um rápido levantamento das políticas do Governo Lula para o financiamento da educação, apontando o caráter vago e lacônico do seu programa de governo, a promessa ainda não cumprida de rever os vetos de FHC ao Plano Nacional de Educação, o descumprimento do artigo da lei do FUNDEF que previa o cálculo do valor mínimo nacional e, portanto, a fragilidade da proposta do FUNDEB (a proposta de emenda constitucional do PT que pretende sanar os problemas do FUNDEF), que irá exigir muito mais recursos do governo federal, a continuação da redução dos recursos vinculados à educação por meio da prorrogação da Desvinculação da Receita da União até 2007, a proposta de emenda constitucional de fim da gratuidade do ensino superior público e, por fim, a proposta do ministro Tarso Genro de oferecer renúncia fiscal a faculdades privadas em troca da cessão de até $25 \%$ das vagas que o governo federal destinaria a estudantes carentes.

Palavras-chave: Política do Governo Lula. Financiamento da educação.

\section{THE LULA ADMINISTRATION AND EDUCATION: STATE DESERTION CONTINUES?}

ABSTRACT: This paper presents an overview of Luis Inácio Lula da Silva's government policies for education funding, indicating the vague and laconic nature of his government program: the as yet unfulfilled promise of reviewing former president Fernando Henrique Cardoso's vetoes to the National Education Plan; the non-enforcement of the article of law on FUNDEF (Fund for the Maintenance and Development of Basic Education and Teacher's Valorization), which provided for the calculation of the minimum

\footnotetext{
* Doutor em Sociologia pela Universidade de São Paulo (USP), mestre em Educação pela Universidade Federal Fluminense (UFF), e professor da Faculdade de Educação desta Universidade.E-mail: ndavies@uol.com.br
} 
O governo Lula e a educação: a deserção do Estado continua?

national value; the fragility of the FUNDEB proposal (the Workers Party's Constitutional amendment proposal supposed to solve all the FUNDEF problems), which will require far more funds from the Federal Government; the renewal of the Constitutional Amendment that allows the government to manipulate $20 \%$ of what would otherwise be earmarked revenue (the so-called Desvinculação da Receita da União [De-Linking of the Federal Government Revenue]) until 2007; the Constitutional Amendment proposal of abolishing free public higher education; and, finally, the proposal submitted by the Education Minister Tarso Genro of offering tax exemption to private colleges and universities who would reserve $25 \%$ of their vacancies to the Federal Government, for poor students.

Key words: Lula's government policy. Education funding.

$\mathrm{O}$ Governo Lula tem atribuído muitos dos problemas que encontrou à "herança maldita" deixada pelo Governo FHC. No entanto, o breve exame que fazemos de algumas das medidas tomadas pelo Governo Lula, principalmente as relacionadas ao financiamento da educação, mostra a fragilidade da propaganda oficial de atribuir tudo à "herança maldita", como veremos a seguir. Antes de mais nada, cabe ressaltar que as políticas do Governo Lula têm priorizado até agora a geração de superávit fiscal para pagar os juros da dívida externa e interna e, assim, atender aos capitalistas financeiros externos e internos, em nada diferindo do Governo FHC. Em vista dessa prioridade, não surpreende a obsessão de congelamento ou redução dos gastos sociais (porém não os financeiros!) por parte do Governo Lula e, portanto, a busca ou a intensificação de parcerias com o setor privado em todas as áreas, inclusive na educacional, como a renúncia fiscal e a proposta de fim da gratuidade do ensino superior público.

Em primeiro lugar, é bom frisar que o programa do governo na campanha eleitoral ("Uma escola para todos", acessível em www.pt.org.br) era bastante vago na questão do financiamento federal da educação pública. Não prometia aumentar os gastos em educação, mas apenas "re-examinar os vetos de FHC ao Plano Nacional de Educação" (Lei n. 10.172) aprovado em janeiro de 2001, o que, de qualquer maneira, seria medida modesta (o principal veto foi o que previa a aplicação de $7 \%$ do PIB em educação ao final dos

Educ. Soc., Campinas, vol. 25, n. 86, p. 245-252, abril 2004 
dez anos do Plano) e em desacordo com a proposta do Plano elaborado por entidades de trabalhadores da educação no II Congresso Nacional de Educação (CONED), em Belo Horizonte, em novembro de 1997, que previa 10\% do PIB. Entretanto, já se passaram muitos meses desde a posse do governo e até hoje ele não derrubou tais vetos nem sinalizou que o faria, provavelmente porque isso prejudicaria a obtenção dos $4,25 \%$ de superávit primário.

O programa também criticava o Governo FHC por não ter cumprido os dispositivos da Lei n. 9.424, do Fundo de Manutenção e Desenvolvimento do Ensino Fundamental e de Valorização do Magistério (FUNDEF), relativos ao cálculo do valor mínimo anual por matrícula no ensino fundamental e, portanto, à complementação federal devida aos fUndefs estaduais. Porém, em 2003 e 2004 o Governo Lula continuou descumprindo o critério desse cálculo, apesar de ter instituído um grupo de trabalho para o estudo do valor mínimo, que reconheceu a ilegalidade praticada pelo governo federal. A conseqüência é que ele deixou de complementar com mais de R $\$ 3$ bilhões o FUNDEF em 2003 e deixará de fazê-lo com outro tanto em 2004, totalizando no mínimo $\mathrm{R} \$ 6$ bilhões de complementação federal devida porém não realizada só nos dois primeiros anos do Governo Lula. É este descumprimento do cálculo da complementação federal que justifica um forte ceticismo com relação à implantação do Fundo de Manutenção e Desenvolvimento da Educação Básica Pública e de Valorização dos Profissionais da Educação (FUNDEB), a panacéia apresentada pelo PT como solução para os males do FUNDEF. Ora, o FUNDEB, que tramita como a Proposta de Emenda Constitucional n. 112 desde setembro de 1999, irá exigir do governo federal um volume muito maior de recursos do que ele atualmente gasta, para garantir um custo-aluno-qualidade em todos os níveis e modalidades da educação básica. Por isso, é pouco provável que ele seja implantado no atual governo ou nos moldes previstos pela PEC 112. Se ele fosse tão importante, o governo federal teria dedicado a ele o mesmo empenho que teve para aprovar as "reformas" da previdência e tributária, em 2003.

A “reforma” tributária, aprovada pela Emenda Constitucional n. 42, em 19/12/2003, é outra medida prejudicial à educação e não 
O governo Lula e a educação: a deserção do Estado continua?

pode ser atribuída à conveniente "herança maldita" deixada pelo governo FHC, pois desvincula $20 \%$ dos $18 \%$ de impostos que o governo federal é obrigado a aplicar em manutenção e desenvolvimento do ensino. Em 2003, isso significou cerca de R $\$ 4,5$ bilhôes a menos do legalmente devido e, para os anos seguintes, podemos prever no mínimo outro tanto cada ano, isso se o "espetáculo do crescimento" não continuar sendo o da recessão. O prejuízo para a educação teria sido maior se a proposta original da PEC 42 tivesse sido aprovada, uma vez que previa também a desvinculação de $20 \%$ do salário-educação (cerca de $\mathrm{R} \$ 700$ milhões), ou seja, o governo iria embolsar esses recursos para usar como quisesse. Uma compensação parcial, no entanto, foi conseguida por meio da Lei n. 10.832, de $29 / 12 / 2003$, que, ao reter $10 \%$ do salário-educação no Fundo Nacional de Desenvolvimento da Educação (FNDE), aumentou de 33\% para $40 \%$ a cota federal a partir de 2004 , reduzindo, em conseqüência, a cota estadual de $66 \%$ para $60 \%$. É verdade que essa lei corrigiu uma distorção ao repassar diretamente aos municípios a parcela do salário-educação correspondente ao número de matrículas que têm no ensino fundamental, evitando que dependessem de regulamentação por lei estadual (dificultada ou impedida por vários governos estaduais) e que dividissem com os governos estaduais apenas $50 \%$ da cota estadual, conforme previsto na Lei n. 9.766, de dezembro de 1998. É verdade, também, que o governo federal pretende destinar parte significativa dos $10 \%$ retidos no FNDE para financiar o transporte escolar nos municípios.

A diminuição da responsabilidade federal com a educação, em particular com a educação superior, e o incentivo à participação do setor privado ficaram claras em outras medidas também. $\mathrm{O}$ orçamento federal para a educação em 2004, por exemplo, representa uma redução de $13,4 \%$ em termos reais, segundo crítica de deputados do PT ligados à educação (Folha de S. Paulo, 12/11/2003). É verdade que o programa de governo ("Uma escola para todos") não assumiu nenhum compromisso de aumentar as verbas da educação para o setor público. Outra medida foi a defesa do fim da gratuidade do ensino superior público, com a proposta de cobrança dos exalunos de instituiçôes públicas após a conclusão do curso, feita pelo então ministro Cristovam Buarque no primeiro semestre de 2003. Essa proposta, que nada tem de nova na história da educação brasi- 
leira, ganhou um reforço com o documento do Ministério da Fazenda que, divulgado em novembro, criticava a "injustiça social" na composição estudantil das universidades federais, por estas serem freqüentadas por estudantes da elite e, portanto, em condiçóes de pagar faculdade. Toda esta farsa da "injustiça social" (curiosamente, o Ministério da Fazenda não enxerga injustiça social nos juros altos pagos aos banqueiros tupiniquins e estrangeiros) foi para o palco legislativo logo a seguir, em dezembro, com a PEC 217, da deputada federal Selma Schöns, do PT do Paraná, que prevê, entre outras coisas, a cobrança de ex-estudantes de universidades públicas com remuneração acima de um piso. Além dessas medidas e da continuação do arrocho salarial de grande parte dos servidores federais em 2004, o futuro das universidades federais, em vista de declaraçóes recentes de autoridades federais, não parece promissor se os que nela trabalham não reagirem em aliança com outros servidores e trabalhadores de outros setores. José Dirceu, chefe da Casa Civil, declarou em dezembro que o "pau iria comer" nas universidades públicas, promovendo uma "revoluçáa", supostamente para evitar que elas fossem superadas pelas privadas (Folha de S. Paulo, 5/12/2003). No entanto, é mais provável que tal superação aconteça pela compressão dos gastos das federais, por iniciativas como a renúncia fiscal proposta por Tarso Genro, pelas bilionárias e antigas isenções fiscais e previdenciárias de que gozam as instituições educacionais privadas, cujos privilégios até hoje não foram alvo de qualquer medida legislativa do Governo Lula (que foi bastante ágil para combater os "privilégios" dos servidores públicos por meio da reforma da previdência), e pelo financiamento público às instituiçóes privadas (FIES). José Dirceu não explicou bem o que queria dizer com o "pau vai comer", mas certamente boa coisa não era nem é, sobretudo porque o seu chefe, o metalúrgico de mais de 20 anos atrás, Lula, declarou, para justificar a nomeação de Tarso Genro, que não queria um acadêmico para fazer a reforma universitária.

Nas privadas, no entanto, é pouco provável que o "pau vá comer", embora nelas o padrão de qualidade esteja longe do ideal para capacitar o Brasil para a "competitividade e excelência supostamente necessárias para enfrentar os desafios da globalização atual" (sic), conforme mostrou o Provão nos últimos anos e as denúncias de entidades como a OAB. Ao contrário, o financiamento ao estudante do 
O governo Lula e a educação: a deserção do Estado continua?

ensino superior privado (FIES) cresceu significativamente neste ano, com previsão de $\mathrm{R} \$ 871$ milhões. No caso do antigo Crédito Educativo (CREDUC), antecessor do FIES e que existiu até abril de 1999, o governo permitiu, por meio da Medida Provisória n. 141, de $1^{\%} / 12 / 2003$, uma negociação entre a Caixa Econômica Federal e os inadimplentes, que resultará num desconto significativo da dívida, estimada em cerca de $\mathrm{R} \$ 2$ bilhões em 2003. Em outras palavras, mais uma vez o prejuízo será socializado, pois o dinheiro público que financiou as mensalidades em faculdades particulares não voltará aos cofres públicos. Além disso, as escolas privadas continuam sendo beneficiadas com uma série de isençôes fiscais (para todas que se definam como sem fins lucrativos) e previdenciárias (só para as declaradas filantrópicas), de incentivos dados pelo governo federal e por governos estaduais, e pelo controle privado de órgãos como os Conselhos de Educação, responsáveis por autorização, reconhecimento e credenciamento de cursos e instituiçôes e que, juntamente com outros fatores, explicam a astronômica expansão do ensino superior privado nos anos de 1990.

Como se não bastassem todos esses privilégios, o governo federal resolveu oferecer mais um, com um verniz democratizante, pois se intitula "Universidade para todos", que ainda não é uma proposta bem definida e detalhada, mas apenas uma idéia de renúncia fiscal pelo governo em troca de vagas ociosas em instituiçôes privadas, reservadas, segundo a página do MEC, a estudantes e professores da rede pública e beneficiários da política de cotas e portadores de necessidades especiais. A meta é oferecer 100 mil vagas em 2004 e 400 mil até 2006, oferecidas por vários tipos de instituiçôes privadas em troca de renúncia fiscal pelo governo federal: as com fins lucrativos, as registradas como sem fins lucrativos e as que se apresentam com o disfarce de filantrópicas, que poderiam assim sair da ilegalidade, segundo o ministro Tarso Genro, que apontou ainda diversas vantagens para essa troca: (1) as privadas resolveriam o problema que enfrentam de vagas ociosas, que seria de $37,5 \%$, segundo o Programa; (2) é mais barato para o governo comprar tais vagas nas privadas que investir nas públicas - $\mathrm{R} \$ 50$ milhôes de renúncia fiscal garantem 100 mil vagas nas privadas, ao passo que para conseguir este número nas públicas seriam necessários $\mathrm{R} \$ 350$ milhões; (3) as vagas nas privadas seriam conseguidas imediatamente, ao pas- 
so que nas públicas isso levaria muito mais tempo. Até o início de março de 2004 essa idéia do ministro não havia sido formalizada como proposta, porém já teria recebido uma acolhida favorável de entidades representativas do setor privado, como a Associação Brasileira das Universidades Comunitárias (ABRUC) e Associação Nacional das Universidades Particulares (ANUP), embora com uma ou outra ressalva, como a de que a idéia ainda está "confusa", como reconhece inclusive o ex-ministro Cristovam Buarque em declaração recente.

É interessante notar a sensibilidade de Tarso Genro para a ociosidade das privadas, que vêm enfrentando também inadimplência superior a $30 \%$, segundo o noticiário dos últimos meses. Como se um ministro tivesse que estar preocupado com o problema das privadas! Com relação ao suposto custo menor de geração de vagas nas privadas que nas públicas, é sempre bom lembrar que as públicas realizam atividades (pesquisa, atendimento médico em hospitais universitários, por exemplo) que, justamente por serem mais dispendiosas, não atraem o interesse da imensa maioria das privadas, que preferem se concentrar apenas no ensino, atividade mais econômica e industrializável. Portanto, se é verdade que o custo para criar uma vaga nas públicas é maior, é preciso ter em conta estes e muitos outros fatores, convenientemente não captados por um raciocínio puramente economicista e influenciado pela perspectiva neoliberal de contenção de gastos sociais. Mais grave, no entanto, é o ministro não reconhecer a educação pública (em todos os níveis) como um direito da cidadania, que não deve estar sujeito nem à lógica do mercado totalmente livre, sem a ação do Estado, nem à lógica assistencialista/economicista/neoliberal do Estado, que parece inspirar a idéia de renúncia fiscal em troca de vagas para grupos "socialmente desfavorecidos" em instituições privadas, supostamente mais baratas que nas públicas.

Ao contrário do slogan vazio e populista "Universidade para todos", essa medida não se destina a todos, sendo típica da perspectiva neoliberal de focalização dos gastos públicos em grupos supostamente mais carentes, e não de sua universalização. Também é neoliberal ao reduzir a educação e os serviços públicos apenas ao seu aspecto econômico e, pior, economicista, transferindo-a para o setor privado. Também é neoliberal por omitir o papel do Estado na oferta direta 
O governo Lula e a educação: a deserção do Estado continua?

de educação. Diante disso, não podemos ter expectativa favorável da proposta de reforma universitária que o governo vai tentar aprovar a todo custo neste ano (depois das eleições municipais!).

Recebido e aprovado em março de 2004. 